\section{Gender: resolve bias, don't excuse it}

It is difficult to make the claim that the disproportionate number of male reviewers and authors is not indicative of some level of gender bias

(L. Koube Nature 505, 291;

2014). As with many other challenges that female scientists face, the answer lies not in explaining why discrepancies exist, but in taking steps to resolve them.

The proportion of female referees ( $13 \%$ for Nature in 2013; Nature 504, 188; 2013) remains considerably lower than the proportion of female researchers (roughly $30 \%$ in the United States, according to a 2013 report by the US National Science Foundation on Women, Minorities, and Persons with Disabilities in Science and Engineering). Not challenging this situation is tantamount to declaring that the quality of the pool of female referees is lower than that of their male counterparts, which is both short-sighted and wrong.

Arguments about personal or family responsibilities only serve to cloud the bigger issue, which is about finding a way to work towards a body of scientific literature that represents true gender balance among those contributing to it.

Morgan V. Fedorchak

University of Pittsburgh,

Pennsylvania, USA.

mod8@pitt.edu

\section{Gender: why publish an offensive letter?}

I want an answer to this question. If the answer was to engender controversy, then it worked; but if it was to reinforce Nature's "own positive views and engagement in the issues concerning women in science" (Nature 505, 483; 2014), then it failed. Here is the context: two weeks ago, Nature published a Correspondence from Lukas
Koube (Nature 505, 291; 2014), which in my view implies that journals' pursuit of scientific quality will logically and inevitably result in women's invisibility. On the day that I read it, I was scheduled to do an interview about my research for the Careers section of Nature. I declined the interview.

Declining this interview was a strategic decision. Every young scientist is told that publication in Nature is a valuable prize, a harbinger of 'glory, laud and honour' and of job security. Thus, the assignment of a Nature DOI (digital object identifier) is a powerful force of reification, one that endures far beyond any squabbling that may precede or follow it.

Nature states that the correspondence it publishes does not necessarily reflect the opinions of the journal or its editors (Nature 505, 483; 2014). However, people have a deepseated tendency to associate the Nature brand with a stringent selection process for publication. Out of the many letters it receives, why did Nature want its readers to read Koube's? It is unclear why you should publish his Correspondence at all in an age when people's comments already have multiple outlets for mass distribution. My interview cancellation was meant to provide concrete evidence that at least one reader wants an answer.

Nature is a powerful institution in which its editors, reviewers, authors and readers invest a monumental amount of effort and care. For this very reason, it is also an institution at which each editorial choice merits exceptional scrutiny.

A. Hope Jahren University of Hawaii, USA. jahren@hawaii.edu

\section{Plume hypothesis challenged}

The hundreds of Earth scientists who challenge the existence of plumes of hot rock rising from
Earth's core-mantle boundary are not "a small but vocal subset" (Nature 504, 206-207; 2013). Rather than simply promoting the conventional wisdom, you should be encouraging the development of multiple working hypotheses.

Many scientists have valid concerns that the originally postulated behavioural, geometric, chemical and thermal characteristics of mantle plumes have been widely discredited (W. J. Morgan and J. P. Morgan in Plates, Plumes, and Planetary Processes 65-78; Geological Society of America, 2007). The plume model has survived only by diversifying its supposed characteristics, which include a variety of compositions and feats such as tunnelling thousands of kilometres horizontally to emerge anywhere at any time, splitting, merging and pulsing (E. R. Lundin in 52 Things You Should Know About Geology 66-67; Agile Libre, 2013).

There are no chemical or isotopic data that require deepplume origins or anomalously high temperatures, and no reliable seismic-tomography results have ever revealed a plume. Plumes cannot account for the eruption rates of the largest flood basalts, which can best be explained by rapidly draining reservoirs of molten rock that have accumulated over long periods.

There has been significant progress in developing an alternative model for anomalous volcanism (see, for example, G. R. Foulger Plates vs Plumes: A Geological Controversy, Wiley-Blackwell; 2010). This is better explained as a passive response to the stretching of lithospheric plates - for example, at rift valleys - which permits melt to rise from shallow depths in the mantle.

Gillian R. Foulger Durham University, UK.

g.r.foulger@durham.ac.uk Warren B. Hamilton Colorado School of Mines, USA.

\section{Cut costs with open- source hardware}

Sally Tinkle and others (see Nature 503, 463-464; 2013) highlight the importance of open-source software and data sharing in materials science. But researchers should also be developing free and open-source hardware to radically reduce the costs of their experimental work.

Harnessing open-source methodology will ensure that funding used to develop scientific equipment is spent only once. A return on investment is achieved through digital replication of devices for just the cost of the materials required. This scaled replication saves $90-99 \%$ on conventional costs, making more scientific equipment available for research and education (see J. M. Pearce Open-Source Lab, Elsevier; 2013).

Dozens of free open-source designs for lab equipment already exist. For example, the University of Washington in Seattle has produced a magnetic rack for molecular and cellseparation applications that can be fabricated with a threedimensional printer for less than it can be bought commercially. Even if the device is made only once, it justifies the price of the printer. A hand-held opensource colorimeter built in my department for US\$50 matches the performance of similar tools that cost more than $\$ 2,000$. And the University of Cambridge, UK, has developed a microscope for about $\$ 800$ from opensource plans, to use instead of conventional equivalents costing up to 100 times as much.

Federal funding agencies could join forces to fund opensource scientific hardware to accelerate its development. A free online database of tested and validated tools should be set up, and governments should give preference to funding such hardware purchases.

Joshua M. Pearce Michigan Technological University, USA. pearce@mtu.edu 